\begin{tabular}{ccc}
\hline International Journal of Engineering \& Technology, 7 (4.7) (2018) $468-471$ \\
SPC & Website $w$ ww.sciencepubco.com/index.php/IJET \\
Research paper & Technology \\
\hline
\end{tabular}

\title{
Augmented Reality (AR) Sandbox: 3-Dimensional Media to Learn Topographic Maps
}

\author{
Dian Septi Nur Afifah ${ }^{1 *}$, Muhammad Ilman Nafi'an², Tri Linggo Wati ${ }^{3}$, Novia Ariyanti ${ }^{4}$, Sutopo $^{5}$ \\ ${ }^{I}$ Mathematics Education Department, STKIP PGRI Tulungagung, Tulungagung, Indonesia \\ ${ }^{2}$ Mathematics Education Department, STKIP PGRI Tulungagung, Tulungagung, Indonesia \\ ${ }^{3}$ Elementary School Teacher Education Department, Universitas Muhammadiyah Sidoarjo, Sidoarjo, Indonesia \\ ${ }^{4}$ Informatics Department, Universitas Muhammadiyah Sidoarjo, Sidoarjo, Indonesia \\ ${ }^{5}$ Mathematics Education Department, Universitas Negeri Malang, Malang, Indonesia \\ *Corresponding author E-mail: dian.septi@stkippgritulungagung.ac.id
}

\begin{abstract}
This research focuses on the literature on the introduction of learning media or apparatus that can introduce topographic maps through augmented reality sandbox in 3-dimensional form. The study presents a specific AR system called Augmented Reality (AR) Sandbox. Data analysis through source triangulation techniques. By validating media feasibility, the AR sandbox is classified as a good learning device when used in learning topographic maps or learning to recognize the shape of the earth's face. However, based on the review literature in these two literature, it has not provided much or less complete references because of the limitations of device development. By using this media, students can distinguish how the shape of the highlands and lowlands, or know the conditions in the ocean to the sea trench.
\end{abstract}

Keywords: Augmented Reality Sandbox, Topographic Maps, AR, 3 Dimensional

\section{Introduction}

Technology has become an inseparable substance to society nowadays, because they have been accustomed to being supported by technology in various situations and activities [1]. Levers or machines and computers become part of daily activities, especially social life. Besides in social life, technology develops in educational activities, i.e. in the teaching and learning process. This digital world also automatically impacts on programs in educational institutions. Digital learning is not only optional, but it is the method needed in schools, colleges and universities because it offers new experiences, unconventional approaches for students of any age, and an increase in their motivation to learn. The teacher uses technology to deliver material clearly so that students understand the purpose of the material. At this time, without direct human interaction can be implemented through the visual world, augmented reality (AR) is just one small part of the world of great technology [2]. Thus, it can be concluded that the study design study using learning based Augmented reality led to an increase in the hypothesis of activity [3].

As part of 21 st century technology, augmented reality has an impact on increasing classroom activity. Although its development began in the 1990s, AR systems have experienced significant development and their daily use is commonplace. AR design principles, i.e. giving challenge, fantasy, and look at the invisible part for the user [4].The sharp difference between the virtual world and the real world in the past has now faded because there has been a successful attempt to combine them.

Students in Indonesia learn about geography only through a map or atlas in $2 \mathrm{D}$, so students do not understand the original form of the map. Furthermore, students are required to be able to understand the state of the earth, such as the difference between lowland and highland.

Aside from 2-dimensional Atlas, students nowadays can use Google Earth / Map in 3-dimensional form. Google earth is a virtual globe based $3 \mathrm{~d}$ maps and geographic information program. However, students cannot measure heights to determine the differences between the highlands and lowlands.

In the last decade, several models of mathematics learning media have been developed to recognize 3D geographical positioning via topographic maps [5]. However, for information reasons, satellite sensors are limited to several new high-resolution satellites. The need to change the mathematics learning media model for different satellite sensors and the need for special software, the use of empirical mathematics learning models through satellite sensors has increased [6].

At present, the discussion is not only limited to paper maps, but also about all methods of data representation through topographic maps [7]. Regardless of the mapping technology used, the first thing to understand when we talk about material for children is how they see danger, what their visual associations are about the type of disaster, and what will help save their lives when a disaster occurs.

Because of the lack of effectiveness when using topographic maps through satellite sensors via Google Earth and the like, this requires a modification of topographic maps with augmented reality, which is in the form of augmented reality sandbox.

This paper aims to focus on the literature on the introduction of media or learning tools that can introduce topographic maps through augmented reality sandboxes in 3-dimensional forms. In this study, the specific AR system is called Augmented Reality Sandbox (AR) Sandbox. A detailed description will be given of some literature or research and the concepts it represents in order 
to be used as an educational tool in the introduction of topographic maps to the students.

\section{Method}

This study applies a qualitative method because the data obtained in this research are qualitative [8], which is in the form of data from several sources analyzed by source triangulation techniques. The sources obtained are 2 sources that discuss Augmented reality sandbox in topographic mapping models from Savova and Hasan Rosyadi.

Augmented reality sandbox validation is conducted to find out whether the device can be a topographic maps learning tool in Indonesia with several aspects such as usability, effectiveness, basic materials, and learning content.

The validation assessment of augmented reality sandbox is integrated with the feasibility and assessment test of Arikunto with the formula shown in figure 1 and the table of media eligibility criteria in table 1 [9].

$$
\bar{x}=\frac{\sum x}{n}
$$

Figure 1: Media aligibility formula

Table1: media eligibility criteria

\begin{tabular}{ll}
\hline Score $(\%)$ & Category \\
\hline $0-20$ & Completely ineligible \\
\hline $21-40$ & Ineligible \\
\hline $41-60$ & Quite ligible \\
\hline $61-80$ & Eligible \\
\hline $81-100$ & Very Eligible \\
\hline
\end{tabular}

\section{Results and discussions}

\section{What Is Augmented Reality Sandbox?}

AR Sandbox is an impressive way to present topographic models. The best quality of this system is that when changing sand in a box, users also change virtual isolines and hypometric coloring on a real time basis. Relief in the sandbox recalibrates based on depth data, which is felt by the Kinect Camera and processed by the software at any time. After these steps, it is given from a data projector above the sandbox, which describes virtual assistance that really fits above the sand landscape. The developer gives users who make their own sandbox, an option to adjust the hypometric color scheme, according to their wisdom. This is possible because of a combination of several GLSL shaders [10]. The AR Sandbox uses a computer projector and motion sensing input device (Kinect 3D Camera) mounted on a box of sand. When visitors interact with sand in a box, kinect detects the distance to the sand below and visualizes the elevation model with contour lines and color maps defined by elevation thrown from overhead projectors onto the sand surface. When visitors move sand, the kinect sees change in distance to the sand surface and the projected color and contour lines change.

Figure 4 shows that rainfall occurs when an object of a hand is felt at a certain height above the surface of the sand. Virtual rain looks like blue visualization, glittering on the surface below. Water appears to flow down the slope to the bottom surface. Real models of fluid dynamics have been used to project the depiction of water flow.

This design is based on real computing that uses objects in the physical world that can be manipulated to change or operate computer programs, in this case, landscape cisualization. The camera on the bonnet exhibition is a microsoft kinect camera, the same camera used in video games, using infrared projectors, cameras, and special microchips to track the movement of objects in $3 \mathrm{~d}$.

In 2003, MIT Media Lab: Tangible Media Group began the initial idea of media development through an interactive sandbox that underlies the interactive sandbox. The interactive sandbox consists of five aspects to create Sandscape, using a very expensive Vivid900 Minolta laser as a scanner from an interactive sandbox [11]. The development of the MIT Media Lab inspires the continued development of interactive sandboxes by presenting an interactive sandbox that can show users how turtle eggs hatch so that they become small turtles that will walk into the sea. The development took six years, in 2009, so it was famous for the Disney Enterprises Inc. [12].

This made Oliver Kreylos and his team from the University of California: UC Davis inspired by a video presentation of an early prototype: SandyStation, developed by researchers from the University of West Bohemia, Czech Republic [13]. After that, Kreylos and his colleagues made this idea available to everyone by creating an open-source Augmented Reality Sandbox [14]. Free software, complete installation instructions, and low cost construction elements from the system are the reasons for choosing this specifically to fulfill the idea of presenting children in an interesting and fun way to remember some types of disasters, and use them to introduce topographic maps learning on student.

As for some benefits and benefits during the use of AR Sandbox according to Savova there are 4; which is a transparent optical display, video vision display, visual spatial handheld display, and direct projection use.

Visible optical display: in this case, optical couplers are used, usually semi-silver mirrors or holographic materials, which "provide a direct optical view of the environment, with images produced simultaneously from computer-generated images".

Video display: this is based on a camera, computer and video display. The camera provides a view of the environment, then the computer produces virtual objects and the display combines views to the user. An example can be in the form of an AR book in Figure $4 \mathrm{~b}$.

Displaying handhelds in visual spatial: this is an alternative way to combine computer graphics and the real environment but when using a handheld screen it is tracked without optics or video penetration capability. In this case, the geometric connection between real objects and virtual objects is not very strong.

Direct projection: this technology uses direct graphical projections to the real environment. In this case, augmentation is fulfilled through real surfaces and the combination between real and virtual is felt more naturally by the user.

According to the Olwal classification, AR Sandbox uses the latest technology. Direct light projection is above the real box full of sand and virtual content, which is a virtual topography (Figure 4). On the other side, Hasan Rosyadi applied the AR Sandbox by using some equipment to set it up. For simulation, free software released by UC Davis is used. Sandbox equipment is made by yourself, including sandbox, 3D camera, projector and computer (Figures $2 \& 3$ ). The AR Sandbox requires Linux (preferably Ubuntu or Mint) or the OSX ${ }^{\circledR}$ operating system with the latest computer hardware components such as the Intel Core i5 CPU, 4GB RAM, and enough space for OS installation. The display driver has an important role in the system and Nvidia video cards are preferred for compatible drivers for Linux OS distribution. This software is currently released by UC Davis (USA) (by Dr. Oliver Kreylos) as freeware and includes three components, Kinect driver packages, Vriu software, and SARndbox. The dimensions of the sandbox are $100 \times 0.75 \times 10 \mathrm{~cm}(\mathrm{LxWxH})$ (Figure 2). The material used mainly consists of fine sand mixture (quartz, muscovite, plagioclase) to a depth of about $10 \mathrm{~cm}$, while the total weight of sand is around $200 \mathrm{~kg}$ [15]. 


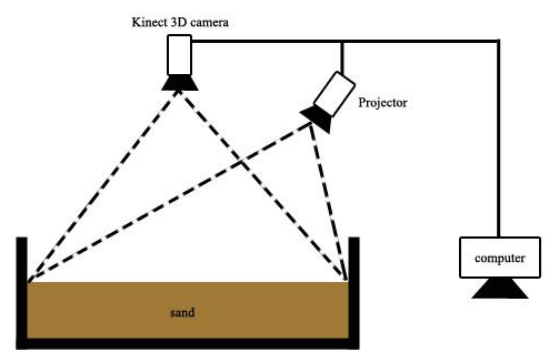

Figure 2: image of AR Sandbox Tools requirement

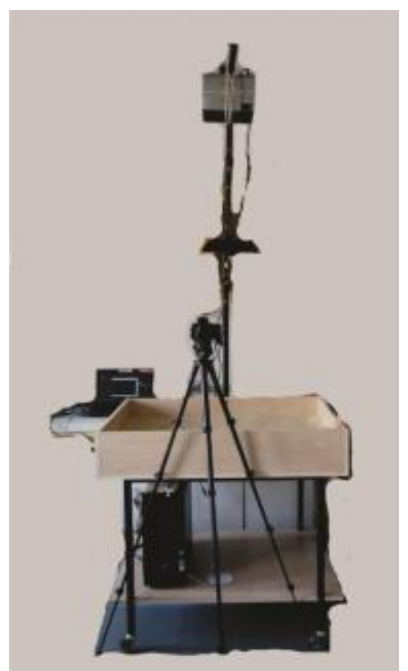

Figure 3: AR Sandbox Tools

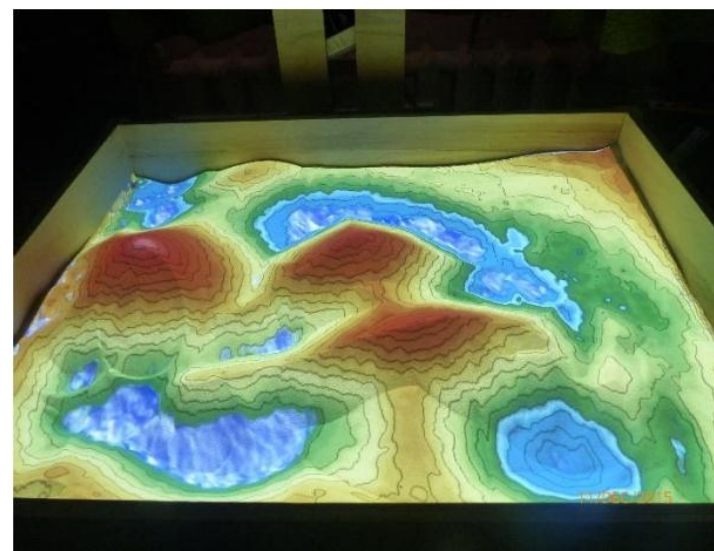

Figure 4: Simulation of Highlands and lowlands Simulasi plateau and lowland on AR Sandbox

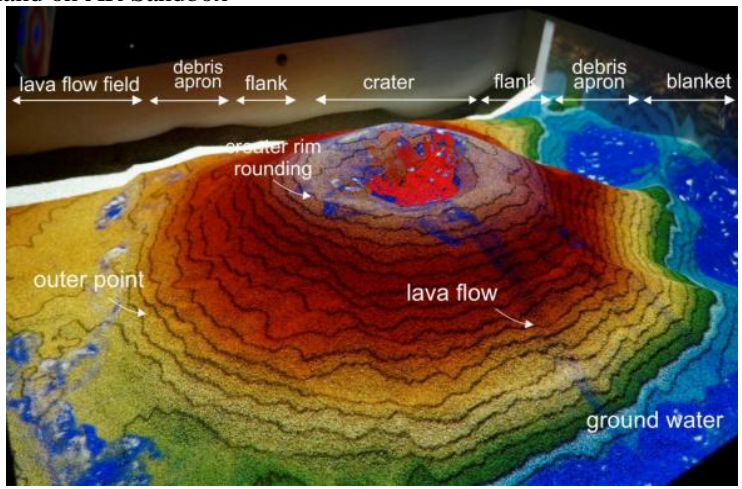

Figure 5: AR Sandbox Simulation, supported with explanations in topographic maps

Validation of Augmented Reality Sandbox

When IT-based learning with augmented / reality is shown to several media experts through learning videos, they provide almost the same response, which is a positive response. The response provides an assessment of the media augmented reality sandbox

Augmented reality sandbox validation is done to find out whether the device can be a topographic maps learning tool in Indonesia with several aspects, namely usability, effectiveness, basic materials, and learning content.

Augmented reality sandbox validation is done by 3 expert validators who are expert lecturers in the field of educational technology at Muhammadiyah University Sidoarjo. Validation results obtained by showing the video using AR Sandbox are presented in table 2 .

Table 2 shows that the AR sandbox is very good to be used as a learning tool for topographic maps in 3-dimensional form in Indonesia, with the consideration that there are usefulness and learning content that become more value than the device. However, another thing to note in using the AR sandbox is that the basic materialss are too expensive to use in Indonesia.

Table2 : The result of Augmented Reality Sandbox validation

\begin{tabular}{llll}
\hline No. & Aspects & Score $(\%)$ & Criteria \\
\hline 1 & Uusage & 86.67 & Very Good \\
\hline 2 & Effectivity & 80 & Good \\
\hline 3 & Basic Materials & 75.33 & Good \\
\hline 4 & Learning contents & 82.67 & Very Good \\
\hline Average & 81.1675 & Very Good \\
\hline
\end{tabular}

\section{Summary}

Savova explained in her research that the sandbox Augmented reality used at the Laboratory of Cartography in UACEG has several potentials with AR Sandbox, namely the reason for exploring ways to be included in new educational programs and activities [2]. In this case, there is only one of the many opportunities where this innovation can be part of modern lessons in school. The Augmented Reality Sandbox is an example that AR is a great tool for presenting specific information to children. Although the work carried out in this direction with the AR Sandbox was only at the level of prototype, the broad interest shown by experts and students is relieving. The listed activities are only one of the many included in the proposal for the Education Disaster Center which will be developed in detail with the help of teachers and psychologists. Furtherly, future work will be focused on trials with children. In the near future, improvements on hardware and software from the AR Sandbox system are not planned but it is expected that in the work process, some ideas for development will emerge and will be fulfilled.

In Hasan Rosyadi's research, it was mentioned that by using the AR sandbox, Rosyadi easily models different fluvial and volcanic settings, which influence the understanding of this arrangement in the concepts of earth science such as geomorphology and topography. Sandbox AR modeling helps to show and observe stable or changing geological settings for users and produce a good understanding and imagination of users to build models that are easy, fast and efficient. In addition, it is helpful to explain and understand complex fluvial systems and volcanoes [15].

From the two literature, it can be said that augmented reality sandbox can be used as a learning tool for topographic maps in 3dimensional form. Students can understand more easily about the lowlands and highlands through sand which is given a color effect through the kinect $3 \mathrm{~d}$ camera.

Both literatures show that there is an ease in using augmented reality sandbox and provide convenience in understanding material such as lowland and highland models and the ocean and their depth. The ease is obtained by adjusting the sand in the box analyzed by the Kinect 3D camera resulted from the analysis of augmented reality emitted by the projector connected from the computer.

The use of augmented reality sandbox includes age restrictions or age grouping on its users. Table 3 explains that the strongest attraction of AR sandbox is the fact that it persuades young 
children and teenagers to get involved. While concepts and scenarios are kept simple for younger children, one can still discuss contour lines, mountain piedmonts, valleys, damages, water flows and basic water flows. When you involve older students or adults, the scenarios and concepts can become more complex. Learning experiences can now include discussions about landscapes, elevations, and best land management practices such as retention ponds and swales. In middle or high schools, learning about processes such as erosion, tectonics, and glaciation can even be visualized. These elements are all the principles of geomorphology, hydrology, earth science and topographic maps.

Table3: Age-grouping in AR Sandbox usage

\begin{tabular}{lll}
\hline No. & Usia & Knowledge \\
\hline 1 & Pre School & $\begin{array}{l}\text { contour lines, piedmonts mountains, } \\
\text { valleys, dams, water flows and basic } \\
\text { water flows }\end{array}$ \\
\hline 2 & Primary student & $\begin{array}{c}\text { Landscapes, elevations and best } \\
\text { land management practices }\end{array}$ \\
\hline 3 & $\begin{array}{l}\text { Secondary / } \\
\text { Higher student }\end{array}$ & Erosion, tectonics and glaciation \\
\hline
\end{tabular}

\section{Conclusion}

AR Sandbox is a 3-dimensional learning tool that can improve learning about fluid and coastal features and processes, and the ability to visualize 3D landscapes from 2D maps called topographic maps. Another invaluable aspect of the Sandbox AR is the opportunity for students to study the movement of virtual water that interacts with the modeled landscape.

Small-scale augmented reality sandbox that accommodates 10 students or less may be the optimal measure to make the most effective use of sandbox, and this will require adjusting a successful exercise with a small group. The abundance of camera phones is an advantage in terms of saving time and sending laboratory exercises for assessment. The use of AR Sandbox can increase the level of comfort of students with this open activity and enable them to use technology effectively.

By validating media feasibility, the AR sandbox is classified as a good learning device when used in learning topographic maps or learning to recognize the shape of the earth's face. However, based on the literature review, these two literature have not provided many references because this media cannot be obtained instantaneously and costs a little, with a series of devices that are easily developed.

In subsequent studies, researchers will seek to use AR sandbox in the teaching and learning process in Indonesia, which is not directly known or experienced at all

\section{Acknowledgement}

We are thank you for Universitas Muhammadiyah Sidoarjo for funded this research publication

\section{References}

[1] M. F. Amir, F. N. Hasanah, and H. Musthofa, "Interactive Multimedia Based Mathematics Problem Solving to Develop Student s ' Reasoning," Int. J. Eng. Technol., vol. 7, no. 2.14, pp. 272-276, 2018.

[2] D. Savova, "AR Sandbox In Educational Programs For Disaster," in 6th International Conference on Cartography and GIS, 2016, no. June, pp. 847-858.

[3] M. F. Amir, C. Chotimah, R. Afandi, H. E. Rudyanto, and I. Anshori, "Design Research Study: Investigation of Increasing Elementary Student' s Spatial Ability Using 3Dmetric," J. Adv. Res. Dyn. Control Syst., vol. 10, no. 6, pp. 1707-1713, 2018.

[4] M. F. Amir, N. Fediyanto, C. Chotimah, and H. E. Rudiyanto, "Developing 3Dmetric Media Prototype through a Hypothetical
Learning Trajector to Train Students Spatial Skill," J. Adv. Res. Dyn. Control Syst., vol. 10, no. 02-Special Issue, pp. 1537-1542, 2018.

[5] T. L. Woods, S. Reed, S. Hsi, J. A. Woods, and M. R. Woods, "Pilot Study Using the Augmented Reality Sandbox to Teach Topographic Maps and Surficial Processes in Introductory Geology Labs," J. Geosci. Educ., vol. 64, pp. 199-214, 2016.

[6] A. Shaker, "Satellite sensor modeling and 3D geo-positioning using empirical models," Int. J. Appl. Earth Obs. Geoinf., vol. 10, pp. 282-295, 2008.

[7] A. K. Y. Li and T. Batchvarova, "Topographic Mappinh and Terrain Modeling from Multi-Sensor Satellite Imagery," Int. Arch. Photogramm. Remote Sens. Spat. Inf. Sci., vol. 37, no. 1, pp. 809814, 2008.

[8] Sugiyono, Metode Penelitian Kuantitatif, kualitatif dan $R \& D$. Bandung: Alfabeta, 2013.

[9] S. Arikunto, Prosedur Penelitian. Jakarta: Rineka Cipta, 2012.

[10] S. Reed et al., "Augmented reality turns a sandbox into a geoscience lesson,” Earth \& Space Science News, 2016. .

[11] H. Ishii, C. Ratti, B. Piper, Y. Wang, and A. Biderman, "Bringing clay and sand into digital design - continuous tangible user interfaces," BT Technol. J., vol. 22, no. 4, 2004.

[12] P. M. Central, "The Most Awesome Sandboxes Ever - Via Projection Mapping," http://projectionmapping.org/the-mostawesome-sandbox-ever/. .

[13] S. Station, "The sandbox in new colors," http://en.sandystation.cz/exhibition/, 2014. .

[14] S. Reed et al., "Shaping Watersheds Exhibit: An Interactive, Augmented Reality Sandbox for Advancing Earth Science Education," Am. Geophys. Union, no. Abstract no. ED34A-01, 2014.

[15] H. Rosyadi and G. Çevik, "Augmented reality sandbox (AR sandbox) experimental landscape for fluvial, deltaic, and volcano morphology and topography models," Turkiye Kuvaterner Sетроzуити, 2016. 